\title{
A saúde do trabalhador na concepção de acadêmicos de enfermagem*
}

\author{
WORKER'S HEALTH IN NURSING UNDERGRADUATES' CONCEPTION \\ LA SALUD DEL TRABAJADOR EN LA CONCEPCIÓN DELACADÉMICO EN ENFERMERIA
}

\author{
Eliana Pinho Azambuja', Nalú P. da Costa Kerber², Ana Lúcia Kirchhof ${ }^{3}$
}

\begin{abstract}
RESUMO
Neste estudo, de abordagem qualitativa, buscamos compreender a concepção do acadêmico de enfermagem do Curso de Enfermagem da Universidade Federal de Santa Catarina sobre saúde do trabalhador. Foram feitas três questões a vinte acadêmicos: $\mathrm{O}$ que entende por saúde do trabalhador? De que forma a enfermagem pode contribuir para a saúde do trabalhador? Qual a relação que existe entre trabalho e estilo de vida? Os resultados foram agrupados nos temas: concepções sobre saúde do trabalhador; papel da enfermagem no contexto da saúde do trabalhador; relação entre trabalho e estilo de vida. Destacamos a inter-relação entre trabalho e estilo de vida, e trabalho e saúde do trabalhador. As reflexões realizadas reforçam a necessidade dessa temática ser discutida nas universidades, para que os acadêmicos sejam estimulados a pensar sobre sua saúde desde o início da academia. Assim estimulados, acreditamos que possam incorporar ações de proteção voltadas a sua saúde no trabalho.
\end{abstract}

\section{DESCRITORES}

Saúde do trabalhador.

Estudantes de enfermagem.

Educação em enfermagem.

\section{ABSTRACT}

In this paper, which uses a qualitative approach, we try to understand the conception undergraduate Nursing students at the Federal University of Santa Catarina have regarding worker's health. Three questions were asked to twenty students: What does he/she understand as worker's health? How can Nursing help to improve worker's health? Which is the relation between work and lifestyle? The results were grouped in the following themes: conceptions of worker's health; the role of Nursing in the context of worker's health; and relation between work and lifestyle. We highlighted the interrelation between work and lifestyle, and between work and worker's health. Our reflections reinforce the need to discuss these themes in the universities so that students are stimulated to think about their own health since the beginning of their academic life. That way, we believe that they will be able to incorporate protective actions to their own health in their daily's work.

\section{KEY WORDS}

Occupational health.

Students, nursing.

Education, nursing.

\section{RESUMEN}

En este papel, de abordaje cualitativo, intentamos entender el concepto del curso de enfermería de la Universidad Federal de Santa Catarina sobre la salud del trabajador. Fueron contestadas tres preguntas hechas a veinte académicos: ¿Cuál es tu comprensión sobre la salud del trabajador? ¿De qué forma la enfermería puede ayudar a mejorar la salud del trabajador? ¿Cuál es la relación entre el trabajo y el estilo de vida del trabajador? Los resultados habían sido organizados en forma de temas: conceptos sobre la salud del trabajador; carácter de la enfermería en el contexto de la salud del trabajador y relación entre trabajo y estilo de vida. Destacamos la interrelación entre trabajo y estilo de vida y trabajo con la salud del trabajador. El énfasis a las contemplaciones hechas refuerzan la necesidad que ese tema tiene para ser discutido en las universidades, así como, estimular a los académicos a pensar en su propia salud desde el principio del curso. De esa forma, creemos que puedan incorporar acciones a la protección de su salud en el trabajo.

\section{DESCRIPTORES}

Salud laboral.

Estudiantes de enfermería.

Educación en enfermería.
* Extraído dos dados coletados na disciplina "Contexto Social II", Curso de Enfermagem, Universidade Federal de

Santa Catarina (UFSC).

1 Enfermeira do Colégio Técnico Industrial Prof. Mário Alquati, da Fundação Universidade Federal do Rio Grande (FURG).

Mestre em Enfermagem pela UFSC. Doutoranda da UFSC. Membro dos Grupos de Pesquisa Práxis/ UFSC e LAMSAFIRG Bolsista PQI/CAPES. Rio Grande, RS Brasil.

gama@vetorial.net

2 Enfermeira. Professora do Departamento de Enfermagem da FURG. Mestre em Enfermagem pela UFSC. Doutoranda da UFSC. Membro dos Grupos de Pesquisa Práxis/UFSC e LAMSA/FURG. Bolsista CNPq. Rio Grande, RS, Brasil. nalu@vetorial.net

3 Enfermeira. Professora do Departamento de Enfermagem da UFSC. Mestre em Enfermagem pela UFSC. Doutora em Filosofia pela UFSC Membro do Grupo de Pesquisa Práxis/UFSC. Florianópolis, SC,

Brasil.

kirchhof@terra.com.br 


\section{INTRODUÇÃO}

A saúde humana, no Brasil e no mundo atual, tem uma das suas marcas na forma como o processo de globalização e reestruturação produtiva vem desenhando o modo de vida e definindo outros padrões de saúde-doença das populações $^{(1)}$.

Observamos que as crescentes transformações, de ordem econômica, política, social e técnica, que vêm se processando no trabalho têm exercido forte influência sobre a saúde dos trabalhadores. Entre essas transformações, pode ser citada:

a forma como o trabalho está realizado, suas modificações e as conseqüências para a saúde do trabalhador, além das relações que se estabelecem em diferentes níveis hierárquicos e entre as profissões, e sobre como conciliar as relações pessoais, profissionais e institucionais às novas formas de emprego, à precarização do trabalho e ao aumento do desemprego, bem como à totalidade da vida do trabalhador( ${ }^{2)}$.

A precarização do trabalho caracteriza-se por desregulamentação e perda de direitos trabalhistas e sociais, legalização dos trabalhos temporários e informais. Como conseqüência, observamos o aumento no número de trabalhadores autônomos e subempregados, bem como a fragilização das organizações sindicais e das ações de resistência individuais e/ou coletivas dos sujeitos sociais.

Paralelo a isso, tem havido intensificação do trabalho, aumento da jornada, acúmulo de funções, maior exposição a fatores de risco para a saúde, descumprimento de regulamentos de proteção à saúde e à segurança, diminuição dos níveis salariais e aumento da instabilidade no emprego.

Diante disso, visualizamos uma modificação no perfil de adoecimento e sofrimento dos trabalhadores, traduzido em acidentes do trabalho e em doenças ocupacionais.

Esse panorama faz com que cada vez mais trabalhadores, tanto atuantes em instituições de serviço quanto em instituições que servem de campo de estágio para cursos da área da saúde, desenvolvam estudos a esse respeito. Como trabalhar com essas questões é uma empreitada marcada por avanços, limitações e impasses. Enfrentá-la

é uma tarefa coletiva, que demanda empenho recíproco no estabelecimento de pactos entre centros acadêmicos, instituições públicas e da sociedade civil, particularmente com instâncias organizativas de trabalhadores( ${ }^{(3)}$.

O conhecimento, produzido e reproduzido na área, tem gerado um novo olhar para essa questão. No entanto, apesar dos avanços significativos, a saúde do trabalhador, segundo nossa concepção, está em contínuo processo de construção. Por pensar desta forma, incluímos, nas ativida- des do currículo de graduação do curso de enfermagem, da Universidade Federal de Santa Catarina (UFSC), um trabalho de discussão e compreensão das concepções que permeiam o mundo do acadêmico de enfermagem sobre essa temática. Entendemos ser necessário o envolvimento precoce do estudante com essas questões, a fim de que possa, já nas aulas práticas e nos estágios, desenvolver ações voltadas à própria saúde e poder produzir essas ações quando trabalhador e coordenador de ações de saúde. Como forma de alcançar essa meta, elegemos, como objetivo deste estudo, explicitar a compreensão dos acadêmicos de enfermagem acerca do tema saúde do trabalhador.

\section{MÉTODO}

Este é um estudo de abordagem qualitativa, desenvolvido com acadêmicos da quinta fase do curso de enfermagem, da Universidade Federal de Santa Catarina, durante a abordagem da disciplina Contexto Social II, na qual realizamos estágio de docência do Curso de Doutorado em Enfermagem, Saúde e Sociedade da mesma universidade.

\section{A abordagem qualitativa parte do fundamento de que há uma relação dinâmica entre o mundo real e o sujeito, uma interdependência viva entre o sujeito e o objeto, um víncu- lo indissociável entre o mundo objetivo e a subjetividade do sujeito. O objeto não é um dado inerte e neutro; está possuído de significados e relações que sujeitos concre- tos usam em suas ações ${ }^{(4)}$}

Aproveitamos este momento ímpar de contato com os acadêmicos, em um espaço já aberto de relações, para averiguarmos, junto a eles, o conhecimento prévio acerca do tema saúde do trabalhador. Julgamos importante ter preparado os conteúdos que iríamos trabalhar em sala de aula, de acordo com os interesses e as necessidades dos alunos e, por esse motivo, vimos a oportunidade de, ao fazê-lo, estar escrevendo e discutindo os achados, como forma de compartilhar, com a comunidade acadêmica, dados que podem ser imprescindíveis, não só para a disciplina em questão, mas também para outras disciplinas.

Tentando buscar subsídios para a aula que iria transcorrer sobre conteúdos de saúde no trabalho, solicitamos, aos 20 acadêmicos que se encontravam em sala de aula na semana anterior, que respondessem a três questões: $\mathrm{O}$ que entende por saúde do trabalhador? De que forma a enfermagem pode contribuir para a saúde do trabalhador? Qual a relação que existe entre trabalho e estilo de vida? Eles foram informados de que as respostas não seriam utilizadas para avaliação da turma e assegurados quanto ao anonimato no momento da divulgação dos achados. A resolução 196/96, do Conselho Nacional de Saúde (CNS), foi anteriormente explicitada, já que o estudo envolveu seres humanos ${ }^{(5)}$.

Como os acadêmicos responderam às questões por escrito, reunimos os dados e procuramos, em momento poste- 
rior, categorizar elementos em cada uma das questões. Foram necessárias várias leituras das respostas, para que pudéssemos, através delas, buscar as concepções dos acadêmicos sobre saúde do trabalhador.

\section{RESULTADOS}

Como forma de compilar os resultados, optamos em abordar cada uma das questões investigadas, utilizando-as como categorias no estudo. Estas foram: concepções sobre saúde do trabalhador; papel da enfermagem no contexto da saúde do trabalhador; e relação entre trabalho e estilo de vida.

\section{Concepções sobre saúde do trabalhador}

Ao analisar as diferentes concepções sobre saúde do trabalhador, nos limites oferecidos pelo estudo, enfatiza-se a predominância da influência das condições de trabalho sobre a saúde dos trabalhadores:

É a qualidade de trabalho para o trabalhador, ou seja, as condições em que o mesmo trabalha, se são condições dignas ou não. (Acad. A)

São situações e condições que façam com que o trabaIhador mantenha sua saúde frente ao tipo de serviço que realiza. (Acad. B)

São todas as condições que propiciam uma boa realização do trabalho, tanto internas quanto externas, e que garantem o bem-estar do trabalhador. Condições internas: mobiliário, salário; externas: moradia, transporte. (Acad. C)

Outro aspecto bastante salientado pelos sujeitos do estudo foi a relação da saúde do trabalhador com o bem-estar fisiológico, psíquico e social. Percebem que o trabalhador é um todo, cujas relações extrapolam o ato de trabalhar, atingindo suas dimensões psicológicas e sociais:

É estar em harmonia com o biológico, espiritual, psicológico e social. É estar bem para a realização de suas atividades e para isso é necessário que ele esteja bem, não só no ambiente de trabalho, mas no todo, familiar e social. (Acad. D)

A saúde do ponto de vista do trabalhador pode ser definida como estado de equilíbrio fisiológico-psíquico-mental, que torna o indivíduo capaz de exercer atividades laborativas compatíveis com a sua condição humana. (Acad. E)

Essas falas nos remetem também à questão da capacidade para o trabalho, pois as condições necessárias ao trabalhador para o desempenho de suas atividades são no sentido de estar apto para seu desenvolvimento.

Vários acadêmicos abordaram o ambiente como exercendo influência na saúde do trabalhador:

Ter todo o apoio ambiental, som, luz, movimentos repetitivos.

Tudo em excesso é prejudicial. (Acad. G)
Inclui um ambiente favorável para que o indivíduo desenvolva seu trabalho, com parâmetros de segurança respeitados, sem riscos graves à saúde física e mental do trabaIhador a longo prazo. (Acad. H)

$\mathrm{O}$ ambiente, tais como radiação, contato com sangue e fluidos corporais, entre outros, oferece riscos à saúde dos trabalhadores. Porém, as ações dos trabalhadores diante desses riscos podem ser revestidas de proteção, como aparece nos depoimentos de alguns alunos:

Preocupação com o bem-estar do trabalhador [...] uso de equipamentos e proteção para a realização de seu trabaIho. (Acad. I)

[..] é realizado trabalho de promoção da saúde e prevenção de doenças. No sentido de promover uma vida saudável, além de prevenir possíveis doenças relacionadas ao trabalho realizado. (Acad. J)

Aparece claramente, nos depoimentos, um outro elemento compondo a saúde do trabalhador, que é a reabilitação e o tratamento das doenças já instaladas no corpo do trabalhador:

Prevenção, tratamento e reabilitação de lesões ou doenças que acometem o trabalhador, devido às condições inapropriadas de trabalho ou que ocorrem por ocasião da função que realiza. (Acad. K)

Constatamos, a partir do relato dos acadêmicos de enfermagem, que o ambiente de trabalho envolve, além das questões relativas às condições físicas e materiais, as relações estabelecidas pelos diferentes membros da equipe:

Ter uma relação agradável com o meio em que trabalha, tanto ambiente (local de trabalho), sua relação interpessoal e, ainda, consigo mesmo. (Acad. L)

Na categoria concepções sobre saúde do trabalhador, percebemos que as condições de trabalho e o bem-estar fisiológico, psíquico e social caracterizam-se como grandes marcos, além dos aspectos relativos ao ambiente, à necessidade de proteção, à reabilitação e ao tratamento das doenças, e às relações desenvolvidas no ambiente de trabalho.

\section{Papel da enfermagem no contexto da saúde do trabalhador}

Os acadêmicos de enfermagem, sujeitos do estudo, demonstraram possuir uma noção bem ampla do papel da enfermagem no contexto da saúde do trabalhador. Uma das funções ressaltadas está posta na educação para a saúde, como um instrumento eficaz de promoção da saúde:

Atuando em educação para a saúde com a prevenção e a promoção da saúde, referente ao local de trabalho, prevenção do estresse. (Acad. L)

Através de práticas educativas, onde esclarecemos as dúvidas e explicamos assuntos novos que sejam de interesse aos trabalhadores. (Acad. M) 
Educando da melhor forma possível. Informando sobre equipamento de segurança, postura, tempo de descanso, exercícios. (Acad. G)

Na mesma direção de um processo educativo, os acadêmicos salientam a importância do enfermeiro realizar prevenção de acidentes no próprio local de trabalho:

Evitando acidentes de trabalho por meio de orientações sobre prevenção de acidente de trabalho. (Acad. A)

Prevenir, com relação a acidentes de trabalho que podem vir a ocorrer tanto no ambiente de trabalho quanto na vida pessoal, que podem vir a atrapalhar seu desenvolvimento no trabalho. (Acad. N)

A enfermagem pode fazer um planejamento, um plano de cuidados e atuar na prevenção de acidentes. (Acad. F)

Outra ação visualizada pelos acadêmicos consiste na assistência direta aos trabalhadores acometidos de doenças relacionadas ao trabalho, ou por acidentes do trabalho:

\begin{abstract}
A enfermagem pode contribuir para a saúde do trabalhador, estando presente nos setores de serviço, com o propósito de resolver pequenas intercorrências, com pequenos acidentes com pérfuro-cortantes e/ou cefaléias, prestando assistência contínua, a partir do acompanhamento da saúde individual, com o agendamento de consultas. (Acad. H)
\end{abstract}

Avaliando, acompanhando e prestando assistência ao trabalhador. (Acad. O)

Cuidado na assistência direta ao trabalhador incapacitado de realizar suas atividades. (Acad. D)

Como parte das atividades que podem ser desenvolvidas pelo enfermeiro, os acadêmicos manifestam a possibilidade de formação de grupos de apoio ao trabalhador que já vivenciou acidentes do trabalho ou que apresenta doença crônica, como mostra a fala a seguir:

Criar grupos de apoio para os trabalhadores que já apresentam a saúde abalada de alguma forma. (Acad. B)

Aparece, nos depoimentos dos sujeitos do estudo, a preocupação com as condições do ambiente de trabalho como um dos papéis do enfermeiro no cuidado à saúde do trabalhador:

Avaliando as condições de trabalho, orientando para condições melhores de trabalho. (Acad. A)

Através da ação em demonstrar pontos insalubres no ambiente de trabalho, nas atividades de prevenção de acidentes e monitoramento do estado de saúde do trabalhador. (Acad. P)

Em relação ao papel da enfermagem na saúde do trabalhador, como pudemos perceber nos temas que foram abrangidos pelos acadêmicos, destacaram-se a educação para a saúde, a prevenção de acidentes, a assistência direta, a formação de grupos de apoio e a preocupação com as condições de trabalho como sendo as atividades predominantes da enfermagem nesse tipo de trabalho.

\section{Relação entre trabalho e estilo de vida}

No cotidiano de vida e trabalho, é determinante a forma e o estilo de postura dos trabalhadores diante das situações vivenciadas, na maneira de conduzir suas atividades. Os acadêmicos de enfermagem, ao manifestarem-se sobre essa questão, deixaram transparecer a inter-relação entre trabalho e estilo de vida:

O trabalho, em seu sentido lato, possui ligação estreita com o modo de vida de seu operador. Este interfere naquele e vice-versa. Muitas vezes, o trabalho efetuado pelos mais diversos tipos de dificuldades, pode condicionar o estilo de vida do indivíduo, limitando suas ações e perspectivas. Da mesma forma, o estilo de vida adotado pelo indivíduo pode contribuir, ou não, para a saúde do trabalhador. (Acad. E)

O estilo de vida adotado vai influenciar diretamente no trabalho, bem como o trabalho, se não for bem feito, poderá influenciar no estilo de vida. (Acad. Q)

Assim como a qualidade do ambiente de trabalho, seus recursos físicos, relações interpessoais e remunerações refletem no estilo de vida do trabalhador, este mesmo estilo de vida influencia no aproveitamento e satisfação, tanto do empregado quanto do empregador e beneficiário, frente ao trabalho desenvolvido. (Acad. R)

Assim como despontou a forte inter-relação entre trabalho e estilo de vida, alguns sujeitos do estudo abordaram o trabalho como um fator determinante do modo de ser e viver dos indivíduos na sociedade:

O trabalho pode ser um determinante em relação à vida que a pessoa pode levar, pois se o trabalho for estressante, a pessoa pode ter uma vida sem qualidades (alimentação inadequada e vida sedentária). (Acad. J)

Tem uma relação muito próxima, pois o trabalho vai refletir no estilo de vida da pessoa. O indivíduo pode ter um estilo de vida inadequado em virtude da obrigação de trabalho. (Acad. A)

Como na maioria das vezes, é o trabalho que rege o estilo de vida de uma pessoa; uma vez que a necessidade financeira e o desemprego não possibilitam sua escolha, este se adaptará ao estresse e à falta de tempo. Os alimentos serão os mais fáceis, acessíveis e mais baratos; as atividades físicas ficarão ausentes, deixadas em segundo plano ou mesmo consideradas desnecessárias; os momentos de lazer ficarão restritos a poucas vezes por mês; o convívio com a família pode se alterar. (Acad. H)

Por outro lado, houve o manifesto de que a forma de viver dos indivíduos, afeta, sobremaneira, seu desempenho no trabalho: 
Se o trabalhador tem bons hábitos relacionados ao seu estilo de vida, vai ser mais produtiv; como conseqüência vai ter mais disposição e menos doença. (Acad. D)

Uma pessoa com bons hábitos de vida, que tem hábitos saudáveis, pratica atividades físicas, não possui vícios, dificilmente será alvo de doenças que prejudiquem seu trabalho. Ao contrário, faz com que este trabalhador tenha disposição, produza mais, faz com que o serviço renda lucros. (Acad. I)

Está provado que pessoas sedentárias estão mais sujeitas a sofrer os danos do estresse. Então, pessoas sedentárias, muitas vezes obesas, sofrendo de estresse, acabam adoecendo mais fácil, o que não é bom nem para o empregador nem para o trabalhador. (Acad. C)

Percebemos, também, nas falas dos sujeitos, a influência do trabalho no processo saúde-doença dos trabalhadores:

Um exemplo são os trabalhadores que trabalham em minas, correndo o risco de adquirirem alguma patologia. Muitas vezes, este mesmo trabalhador não tem tempo para um lazer, por exemplo. (Acad. A)

O trabalho pode interferir nas condições de saúde do indivíduo. (Acad. T)

A inter-relação entre trabalho e estilo de vida foi efetuada de maneira significativa pelos acadêmicos, sobressaindo, também, o trabalho como fator determinante do modo de ser e viver, a forma de viver afetando o desempenho no trabalho e a influência do trabalho no processo saúde/ doença dos trabalhadores.

\section{DISCUSSÃO}

A seguir, apresentamos a discussão reflexiva sobre os achados encontrados:

\section{Concepções sobre saúde do trabalhador}

Os acadêmicos de enfermagem concebem o campo da saúde do trabalhador como vinculado às condições e ao ambiente de trabalho, ao bem-estar psicológico, fisiológico e social, ao uso de medidas de proteção, às relações estabelecidas no trabalho e ao espaço de reabilitação e tratamento de doenças ocupacionais. Consideramos que há um entendimento amplo acerca dessa questão, vindo ao encontro do que é referido na literatura pesquisada, como, por exemplo:

O termo saúde do trabalhador refere-se a um campo do saber que visa compreender as relações entre o trabalho e o processo saúde/doença. Nesta acepção, considera a saúde e a doença como processos dinâmicos, estreitamente articulados com os modos de desenvolvimento produtivo da humanidade em determinado momento histórico. Parte do princípio de que a forma de inserção dos homens, mulheres e crianças nos espaços de trabalho contribui decisivamente para formas específicas de adoecer e morrer(6)
Um dos autores estudados ${ }^{(7)}$, ao refletir sobre a saúde do trabalhador, enfatiza que é preciso considerar a saúde como algo mais amplo do que ausência de doenças. Assim percebida, as estratégias de intervenção passam a centralizar-se não mais em ações puramente individuais, mas adquirem um caráter coletivo.

Nesse sentido, a visão apresentada pelos acadêmicos participantes deste estudo, por considerar aspectos coletivos na produção da saúde do trabalhador, traz, em seu bojo, essa necessidade de que as ações voltadas à saúde do trabalhador sejam desenvolvidas, considerando não só as situações de risco, mas igualmente a organização do trabalho.

Refletindo sobre uma das questões apontadas no campo da saúde do trabalhador há o relato de que as condições de trabalho podem referir-se

à realização da tarefa em si, à infra-estrutura física, aos recursos materiais, ao quadro de pessoal qualitativo e quantitativo, à política institucional, aos benefícios oferecidos aos trabalhadores ${ }^{(2)}$.

Os participantes restringem essas condições de trabalho basicamente a elementos como o ambiente físico e os equipamentos. Isso não significa que não visualizem a falta de recursos humanos ou a própria organização do trabalho como influenciadores da saúde dos trabalhadores; mas pode ser apenas que ainda não consigam apreender essa dimensão.

Nas relações estabelecidas entre trabalho e processo saúde/doença, os acadêmicos extrapolam a conceituação trazida, no sentido de perceberem o trabalhador como um todo, ou seja, todas as esferas que compõem sua existência precisam estar em equilíbrio para garantir o desempenho necessário no cotidiano de trabalho. Isso significa dizer que consideram os indivíduos como seres que não podem ser descontextualizados do seu processo de viver e nem ser considerados apenas trabalhadores, pois qualquer uma de suas vivências externas ao ambiente de trabalho pode afetar a qualidade do mesmo.

Outro aspecto apontado como fazendo parte da concepção de saúde do trabalhador refere-se às relações estabelecidas no local de trabalho. Um acadêmico, ao manifestarse sobre isso, enfatiza a importância de existir uma relação agradável com o meio, com os colegas e consigo mesmo, para que o trabalhador sinta-se saudável.

É possível perceber, no nosso cotidiano de trabalho, que aqueles ambientes permeados por uma relação conflituosa ou de desrespeito tornam-se ambientes pesados, estressantes, causadores de desgaste no trabalhador. A interação social faz parte do trabalho e coloca-se como um importante instrumental para o desenvolvimento tranqüilo e prazeroso das atividades cotidianas.

Quando um dos autores estudados ${ }^{(8)}$ vai buscar subsídios para abordar a questão do relacionamento com colegas 
em seu estudo, o faz baseado nas idéias de outros autores $^{(9)}$, os quais observam que o relacionamento entre o grupo é um fator importante para a construção de ferramentas cognitivas individuais.

Apesar de concordarmos com a importância de haver um bom relacionamento no grupo de trabalho, precisamos refletir que:

trabalhar relações não é algo fácil, suplantar questões pessoais, enfrentar os problemas de ordem profissional com a maturidade necessária, implica reconhecer os limites do outro, ter respeito às diferenças, buscar somar em vez de dividir, sem esquecer que as dimensões pessoais, profissionais e institucionais estão presentes no cotidiano de trabalho ${ }^{(2)}$.

\section{Papel da enfermagem no contexto da saúde do trabalhador}

Compondo essa categoria, há a explicitação da educação em saúde, da prevenção de acidentes, da assistência direta ao trabalhador, da formação de grupos de apoio e da preocupação com as condições do ambiente.

A educação aparece muito vinculada ao modelo tradicional, com o enfermeiro no papel de transmissor de conhecimentos. Nesse modelo há uma unidirecionalidade do educador em relação ao educando, não havendo trocas de saberes nem construção coletiva do conhecimento.

No entanto, sabemos que o conhecimento do trabalhador é fundamental para que haja mudança na realidade, o que pressupõe sua participação efetiva no processo educativo. Entendemos que essa educação participativa contém potencial para desenvolver, nos trabalhadores, capacidade crítica diante do cotidiano do trabalho. Essa postura crítica fará com que os trabalhadores atuem diante das situações de risco de forma a evitar os adoecimentos e acidentes de trabalho.

O desenvolvimento de ações educativas voltadas à prevenção de acidentes é outra função atribuída à enfermagem, pelos acadêmicos. Isso reforça a necessidade de que as ações de prevenção sejam construídas coletivamente, envolvendo os diferentes trabalhadores da enfermagem, num processo contínuo de (re)conhecimento das diferentes situações de risco presentes no ambiente do trabalho. Para o encaminhamento e a efetividade de ações de vigilância da saúde do trabalhador, há a necessidade de estabelecer parcerias, principalmente com os trabalhadores, que são os maiores interessados $^{(7)}$. Além disso, há a necessidade de extrapolar os diferentes ambientes de trabalho e buscar a inserção da população com um todo, na luta por melhorias nas políticas que direcionam a saúde do trabalhador.

Destacamos a reflexão quanto à abrangência das ações de vigilância em saúde do trabalhador $(\mathrm{VST})^{(10)}$ :
[...] a VST é um processo social contínuo em que vários atores, inclusive a sociedade, executam o seu protagonismo cotidianamente em níveis distintos de ação e com integrações organizadas por processos de promoção da saúde ou de reprodução do capital, em contextos perceptíveis e imperceptíveis se tocando continuamente.

Ainda nesse contexto, os acadêmicos enfatizam a assistência direta aos trabalhadores que sofreram acidentes do trabalho ou foram acometidos de doenças relacionadas ao trabalho.

Deixam clara a necessidade da existência de um setor específico voltado à saúde do trabalhador, objetivando garantir a promoção e a manutenção da saúde. Pensam que, dessa forma, possa haver a prestação de uma assistência contínua, com avaliação e acompanhamento constante do trabalhador, ou seja, as ações voltadas à saúde do trabalhador ocorreriam de forma sistematizada, e não só nos momentos pontuais da ocorrência do acidente ou da doença ocupacional. Essas ações podem ser caracterizadas como ações de vigilância e não só de assistência direta, uma vez que através delas as situações estariam sendo identificadas como de risco.

As ações de vigilância em saúde devem ser desenvolvidas de forma articulada entre os trabalhadores, as organizações e as áreas da pesquisa, da assistência e da reabilitação:

A vigilância em saúde do trabalhador compreende uma atuação contínua e sistemática, ao longo do tempo, no sentido de detectar, conhecer, pesquisar e analisar os fatores determinantes e condicionantes dos agravos à saúde relacionados aos processos e ambientes de trabaIho, em seus aspectos tecnológico, social, organizacional e epidemiológico, com a finalidade de planejar, executar e avaliar intervenções sobre estes aspectos, de forma a eliminá-los ou controlá-los ${ }^{(6)}$.

Uma das ações que os acadêmicos salientam como sendo do papel do enfermeiro é a possibilidade de formação de grupos de apoio aos trabalhadores que apresentam algum comprometimento de sua saúde. Consideramos tal formação pertinente, uma vez que o trabalhador, inserido nesse grupo, poderia dividir suas ansiedades e dúvidas, ter apoio de outros profissionais e dos colegas, coletivizar sua experiência como forma de tentar evitar a recorrência de vivências semelhantes a sua.

\section{Relação entre trabalho e estilo de vida}

É possível perceber, através da análise dos depoimentos, os seguintes aspectos: inter-relação de trabalho e estilo de vida, o trabalho como fator determinante do modo de ser e de viver dos trabalhadores e a influência do trabalho no processo saúde-doença dos trabalhadores. 
Os acadêmicos consideram que, dependendo da forma como cada trabalhador desempenha as atividades, pode haver uma interferência na forma dele viver no ambiente externo ao trabalho, ou seja, as condições nas quais o trabalho é desenvolvido, a remuneração que advém daí, enfim, a forma como o trabalho é organizado, tudo interfere sobremaneira no estilo de vida do indivíduo. Por vezes, o trabalhador, ao experienciar condições não favoráveis no ambiente de trabalho, tendo remuneração precária, pode não ter condições psíquicas ou econômicas de ter uma vida saudável.

As diferentes vivências no ambiente do trabalho podem interferir, portanto, na vida familiar e social, uma vez que o indivíduo é único e total na vivência dos diferentes espaços que compõem sua existência.

Por outro lado, entendemos que cada indivíduo, independentemente do trabalho que desenvolve, pode viver de tal forma que venha a ter um prejuízo na sua saúde, como, por exemplo, sendo sedentário, tendo vícios ou não se alimentando adequadamente. Ao aproximarmos essa questão com o trabalho, percebemos a forte relação existente entre eles, pois um indivíduo mal alimentado, que necessita caminhar por longos períodos em sua jornada de trabalho, sem que esteja acostumado a realizar exercícios físicos, certamente terá maiores dificuldades para desempenhar suas atividades com segurança e tranqüilidade.

Os acadêmicos deixam claro a interface existente entre estilo de vida e trabalho, ressaltando o quanto é forte a interferência de um sobre o outro. Assim sendo, concordamos com o conceito de estilo de vida no sentido de um compromisso individual agregado com ações e hábitos que podem afetar a saúde pessoal ${ }^{(11)}$.

Ficou expressa, igualmente, a relação entre estilo de vida e os recursos financeiros que são propiciados através do trabalho. Os acadêmicos avaliam que, sem emprego ou com ganhos financeiros escassos, existirão inúmeras dificuldades para que o indivíduo tenha uma vida saudável. E, por isso, há a conotação de que o trabalho rege o estilo de vida das pessoas. Essa é uma questão que já foi discutida em uma pesquisa realizada com enfermeiros em 2003, na qual há

\section{REFERÊNCIAS}

1. Rigotto RM. Saúde dos trabalhadores e meio ambiente em tempos de globalização e reestruturação produtiva. Rev Bras Saúde Ocup. 1998;(93/94):9-20.

2. Gelbcke FL. Interface dos aspectos estruturais, organizacionais e. relacionais do trabalho da enfermagem e o desgaste do trabalhador [tese]. Florianópolis:Programa de Pós-Graduação em Enfermagem, Universidade Federal de Santa Catarina; 2002. a constatação de que o trabalho é ligado ao retorno financeiro, que é convertido em um local para morar e condições de sobrevivência ${ }^{(12)}$. Inclusive, a retribuição financeira despontou na pesquisa como sendo um dos fatores de maior insatisfação no trabalho do enfermeiro.

\section{CONSIDERAÇÕES FINAIS}

Pelas diferentes reflexões feitas, percebemos que os acadêmicos de enfermagem têm claro, ao pensar saúde do trabalhador, o quanto o trabalho exerce influência no processo saúde-doença dos trabalhadores.

Sabemos que o ambiente de trabalho oferece variados riscos à saúde dos indivíduos, os quais podem ser evitados ou reduzidos através de medidas de proteção, como já abordado anteriormente. Por vezes, no entanto, o trabalhador, por desconhecer ou não identificar determinadas situações de risco, tem ações não revestidas de proteção, as quais podem conduzir a acidentes do trabalho ou doenças ocupacionais como desfecho dessa interação. Esses acidentes ou doenças, além de conter o potencial de impedir temporária ou permanentemente o trabalhador de desempenhar seu trabalho por alterações físicas, podem conduzir a transtornos psíquicos ou emocionais importantes, igualmente portadores da necessidade de afastamento.

Questões como essas, quando se refletem sobre a saúde do trabalhador, precisam ser mais amplamente discutidas nos ambientes de trabalho e nos espaços de formação profissional, de forma a contribuir para organizações que primem pela promoção da saúde no trabalho, bem como favorecer que as relações que se processam entre trabalho e trabalhador sejam harmoniosas e revestidas de proteção.

As reflexões realizadas reforçam a necessidade de que a temática Saúde do Trabalhador faça parte do currículo das escolas de enfermagem, para que os acadêmicos sejam estimulados a pensar sobre a própria saúde desde o início da vida acadêmica. Assim estimulados, é possível que incorporem ações de proteção de saúde no cotidiano de seu trabalho.
3. Minayo-Gomes C, Thedim-Costa C. A construção do campo da saúde do trabalhador: percurso e dilemas. Cad Saúde Pública. 1997;13 Supl 2:21-32.

4. Chizzoti A. Pesquisa em ciências humanas e sociais. $2^{a}$ ed. São Paulo: Cortez; 1995. 
5. Conselho Nacional de Saúde. Resolução n. 196, de 10 de outubro de 1996. Dispões sobre diretrizes e normas regulamentadoras de pesquisas envolvendo seres humanos. Bioética. 1996;4(2 Supl):15-25.

6. Brasil. Ministério da Saúde. Departamento de Atenção Básica. Área Técnica de Saúde do Trabalhador. Caderno de saúde do trabalhador. Brasília; 2001.

7. Alves RB. Vigilância em saúde do trabalhador e promoção da saúde:aproximações possíveis e desafios. Cad Saúde Pública. 2003;19(1):319-22.

8. Alvarez BR. Qualidade de vida relacionada à saúde de trabalhadores: um estudo de caso [dissertação]. Florianópolis: Programa de Pós-Graduação em Engenharia de Produção, Universidade Federal de Santa Catarina; 1996.
9. Mugny G, Doise W. Socio-cognitive conflict and structure of individual and collective performance. Eur Fed Soc Psychol. 1978;(8):181-92.

10. Machado JMH. A propósito da vigilância em saúde do trabalhador. Ciênc Saúde Coletiva. 2005;10(4):987-92.

11. Bouchard C, Shepard RJ, Stephens T, Sutton JR, McPherson BD. Exercise, fitness and health: the consensus statement. Champaign, IL: Human Kinetics; 1990.

12. Batista AAV, Vieira MJ, Cardoso NCS, Carvalho GRP. Fatores de motivação e insatisfação no trabalho do enfermeiro. Rev Esc Enferm USP. 2005;39(1):85-91. 